Check for updates

Cite this: RSC Adv., 2019, 9, 40531

October 2019

Accepted 11th November 2019

DOI: 10.1039/c9ra07970j

rsc.li/rsc-advances

\section{A novel indole-based conjugated microporous polymer for highly effective removal of heavy metals from aqueous solution via double cation $-\pi$ interactions $\dagger$}

\author{
Qiang Wang, (D) Rui Li, Xiao Ouyang and Guojun Wang* \\ A novel indole-based conjugated microporous polymer (PTIA) with three coplanar indole units, designed \\ and synthesized by an oxidative coupling reaction, was utilized as a platform for removing heavy metals. \\ Owing to the conjugation of the three coplanar indoles, the highly electron-rich large $\pi$ planes can \\ simultaneously attract six heavy metal atoms via double cation $-\pi$ interactions, endowing this \\ microporous material with remarkable heavy metal adsorption capacity and efficiency.
}

\section{Introduction}

In recent years, the health of human beings has been endangered by heavy metal ions, and it is therefore very important to remove heavy metals from aqueous solutions due to their toxicity and bioaccumulation..$^{1-4}$ Moreover, excessive intake of heavy metal ions, for example, $\mathrm{Ni}(\mathrm{II}),{ }^{5} \mathrm{Cu}(\mathrm{II}),{ }^{6} \mathrm{Zn}(\mathrm{III})^{7}$ and $\mathrm{Cr}(\mathrm{III})^{8}$ is harmful to humans and other species. A wide range of technologies have been investigated for heavy metal ion removal from water including chemical precipitation, ${ }^{9}$ organic chelation, ${ }^{10,11}$ biological removal, ${ }^{12}$ ion-exchange, ${ }^{13,14}$ membrane separation $^{15}$ and adsorption. ${ }^{16,17}$ Among these approaches, adsorption is found to be the most attractive due to its advantages of relative simplicity, easy scale-up and high efficiency over a wide concentration range..$^{18,19}$ Developing novel efficient, economical, green and environment-friendly adsorbents for heavy metal ions has been considered as an effective way to mitigate the deterioration of the environment. ${ }^{20-23}$ Conjugated microporous polymers (CMPs) have many specific features such as large surface area, high porosity, adjustable pore size, thermal and chemical stability, showing great advantage in removal of heavy metals. ${ }^{24-26}$ However, the inherent physisorptive metal-adsorption mechanism makes them inevitably suffer from low adsorption capacity and efficiency hence severely hampers their practical applications. Compared with adjusting the pore parameters and surface area, according to

Key Laboratory of Superlight Materials and Surface Technology, Ministry of Education, College of Materials Science and Chemical Engineering, Harbin Engineering University, Harbin 150001, China. E-mail:wang5347@hrbeu.edu.cn

$\uparrow$ Electronic supplementary information (ESI) available: Details of preparation and characterization of the TAT and PTIA; pH effect on the removal of $\mathrm{Ni}^{2+}$, $\mathrm{Cu}^{2+}, \mathrm{Cr}^{3+}$ and $\mathrm{Zn}^{2+}$ by PTIA; kinetics data and sorption data of PTIA toward $\mathrm{Ni}^{2+}, \mathrm{Cu}^{2+}, \mathrm{Cr}^{3+}$ and $\mathrm{Zn}^{2+}$; adsorption cycle test and simulation method. See DOI: $10.1039 / \mathrm{c} 9 \mathrm{ra} 07970 \mathrm{j}$ the recent research results, the incorporation of some specific functional groups or heteroatoms into the microporous framework to improve the heavy metals binding affinity has been revealed to be a simple and effective method to enhance the heavy metals adsorption capacity and efficiency. ${ }^{27,28}$ As a typical aromatic compound, indole possesses more rich electronic structure than general aromatic structure,,$^{29-33}$ which makes it more easily to form cation- $\pi$ interaction with cations. Chang et al. has found that the 4-hydroxyindole-formaldehyde aerogel (4-HIFA) containing hydroxyl and electron-rich indole ring possessed strong affinity for heavy metals via the synergistic effects of complexation and cation- $\pi$ interactions, ${ }^{34}$ however, the single cation $-\pi$ interaction means that one indole plane can only attract one heavy metal and the additional functional groups would consume the occupied volume of the porous frameworks, leading to less improvement in the heavy metal adsorption capacities for these indole-based porous materials with multi-functional groups. Based on the work of Chang et al.,$^{34}$ therefore, to better utilize the cation- $\pi$ interactions for developing new heavy metals adsorbent with both excellent adsorption capacity and efficiency still remains attractive prospects and great challenge.

Herein, a new type of indole-based conjugated microporous polymer (PTIA) was designed and synthesized in the presence of the $\mathrm{FeCl}_{3}$ catalyst by a facile direct oxidative coupling reaction (Scheme 1a). We expected that the conjugation of coplanar three indole would form a highly electron-rich large $\pi$ plane which can simultaneously attract six heavy metal via the double cation $-\pi$ interactions, resulting in a great increase heavy metal adsorption capacity and efficiency (Scheme 1b). Because the texture properties of the CMPs are mainly governed by the design or selection of a specific monomer, herein, we used the indole-based monomer 10,15-dihydro-5H-diindolo[3,2-a:3', $\left.2^{\prime}-c\right]$ carbazole (TAT) (Fig. S1, ESI $\dagger$ ), which has a coplanar structure. 


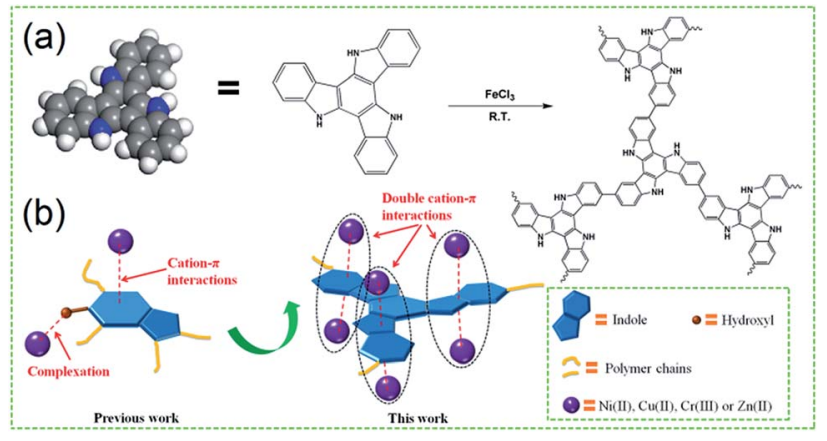

Scheme 1 (a) The coplanar structure of the repeating unit and the synthetic route of the indole-based conjugated microporous polymer (PTIA), (b) schematic illustration of heavy metals adsorption using PTIA via double cation $-\pi$ interactions.

The TAT utilized in the polymerization was synthesized in a single step using 2-indolinone as the monomers. The synthesized TAT was polymerized in the presence of the $\mathrm{FeCl}_{3}$ catalyst by direct oxidative coupling reaction, and the material preparation and characterization are detailed in the ESI $\uparrow$.

\section{Experimental}

The main materials, measurements, synthetic routes of the TAT and PTIA, pH effect on the removal of $\mathrm{Ni}^{2+}, \mathrm{Cu}^{2+}, \mathrm{Cr}^{3+}$ and $\mathrm{Zn}^{2+}$ by PTIA, kinetics data and sorption data of PTIA toward $\mathrm{Ni}^{2+}$, $\mathrm{Cu}^{2+}, \mathrm{Cr}^{3+}$ and $\mathrm{Zn}^{2+}$, adsorption cycle test and simulation method are described in ESI. $\dagger$

\section{Results and discussion}

As shown in Fig. S2 and S3, $\dagger$ the atoms of TIA belonged to aromatic $\mathrm{H}$ and $\mathrm{C}$. The resulting PTIA was characterized by Fourier transform infrared and ${ }^{13} \mathrm{C} \mathrm{CP} / \mathrm{MAS}$ NMR, and the results were in good agreement with the proposed structures (Fig. S4 and S5, ESI†े). The FTIR spectrum of the PTIA is shown in Fig. S4, $\dagger$ in which the absorption peaks at about $3423 \mathrm{~cm}^{-1}$ correspond to the structure of $\mathrm{NH}$ groups. The peak at $1606 \mathrm{~cm}^{-1}$ is attributed to the skeleton vibrations of conjugate structures in the network. As shown in Fig. S5, $\uparrow$ the broad peaks at 150-100 ppm are ascribed to the indole group carbons.

The SEM of the PTIA displays that the material consists of aggregated particles with sub-micrometer sizes (Fig. 1a), and
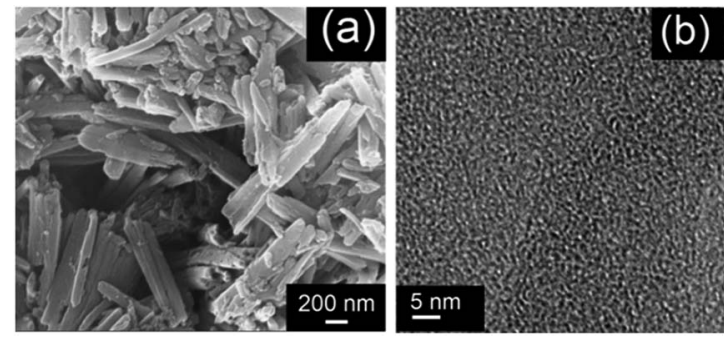

Fig. 1 Micro-structures of the PTIA network. (a) SEM, (b) TEM. the TEM image (Fig. $1 \mathrm{~b}$ and $\mathrm{S} 7 \dagger$ ) is indicative of porous structures of the PTIA material that are essential requirements for removal of heavy metals. The nitrogen adsorption-desorption isotherms of PTIA measured at $77 \mathrm{~K}$ is shown in Fig. S6, $\dagger$ displaying a typical curve of type $\mathrm{I}^{35}$ which is consistent with their expected microporous nature. There are hysteresis loops at relative pressures of $0.2-0.95$, suggesting the presence of mesopores and macropores in the sample, ${ }^{36}$ in good agreement with those observed with the SEM technique (Fig. 1a). The calculation for data showed that the Brunauer-Emmett-Teller (BET) specific surface area of the PTIA is up to $139 \mathrm{~m}^{2} \mathrm{~g}^{-1}$. Additionally, nonlocal density functional theory (NLDFT) was used to approximate the pore size distributions (PSD) of PTIA employing the cylindrical pore-oxide surface model. ${ }^{37}$ The calculation yielded an average pores size of $\sim 1.9 \mathrm{~nm}$ and a sharp peak $\sim 1.92 \mathrm{~nm}$.

It was expected that the resulting PTIA with the conjugation of coplanar three indole would form a highly electron-rich large $\pi$ plane which can simultaneously attract six heavy metal via the double cation $-\pi$ interactions, which inspires us to investigate its heavy metal ions adsorption capacity and efficiency.

The $\mathrm{pH}$ of solution is one of the most important parameters affecting sorption process. Fig. $\mathrm{S} 8 \dagger$ shows the dependences of the adsorption capacity for $\mathrm{Ni}^{2+}, \mathrm{Cu}^{2+}, \mathrm{Cr}^{3+}$ and $\mathrm{Zn}^{2+}$ on the $\mathrm{pH}$ value (2.0-6.0) over PTIA in order to eliminate the effect of precipitation at higher $\mathrm{pH}$ values. Notably, that the ions adsorption of $\mathrm{Ni}^{2+}, \mathrm{Cu}^{2+}, \mathrm{Cr}^{3+}$ and $\mathrm{Zn}^{2+}$ was increased with the increase of $\mathrm{pH}$ value from 2.0 to 6.0. The phenomenon could be explained that at lower $\mathrm{pH}$, the relatively high $\mathrm{H}^{+}$concentration would strongly compete with metal ions for the adsorption sites, resulting in low adsorption capacity. With the increase of $\mathrm{pH}$, the competition between $\mathrm{H}^{+}$and other cations could be neglected. In view of the fact that the precipitation of $\mathrm{Ni}^{2+}, \mathrm{Cu}^{2+}, \mathrm{Cr}^{3+}$ and $\mathrm{Zn}^{2+}$ takes place at $\mathrm{pH} \geq 7, \mathrm{pH} 6.0$ was selected as the optimum $\mathrm{pH}$ for the following batch experiments to eliminate the effect of precipitation.

The adsorption kinetics of the $\mathrm{Ni}^{2+}, \mathrm{Cu}^{2+}, \mathrm{Cr}^{3+}$ and $\mathrm{Zn}^{2+}$ ions by PTIA was investigated in order to study adsorption rate and pathways of adsorption until equilibrium was reached $(240 \mathrm{~min}$ after starting adsorption). The results (Tables S1-S4, ESI $\dagger$ ) and sorption kinetics curves (Fig. 2a) show rapid uptake rates and high removal efficiency. Within $1 \mathrm{~min}$, the PTIA achieved $\geq 97 \%$ removal rates and $K_{\mathrm{d}}$ values of $>10^{4} \mathrm{~mL} \mathrm{~g}^{-1}$ for $\mathrm{Ni}^{2+}$ (Table S1 $\dagger$ ) and $\mathrm{Cu}^{2+}$ (Table S2 $\dagger$ ). Within $5 \mathrm{~min}$, the PTIA achieved $\geq 98 \%$ removal rates and $K_{\mathrm{d}}$ values of $>10^{4} \mathrm{~mL} \mathrm{~g}^{-1}$ for $\mathrm{Ni}^{2+}$ (Table S1 $\dagger$ ) and $>10^{5} \mathrm{~mL} \mathrm{~g}^{-1}$ for $\mathrm{Cu}^{2+}$ (Table S2 $\dagger$ ). Within $30 \mathrm{~min}$, the PTIA achieved $\geq 99 \%$ removal rates and $K_{\mathrm{d}}$ values of $>10^{5} \mathrm{~mL} \mathrm{~g}^{-1}$ for $\mathrm{Ni}^{2+}$ (Table S1 $\dagger$ ) and for $\mathrm{Cu}^{2+}$ (Table S2 $\dagger$ ). For the $\mathrm{Cr}^{3+}$ and $\mathrm{Zn}^{2+}$ ions (Tables S3 and S4 $\uparrow$ ), the adsorption is slightly slow but still has a $97.65 \%$ and $98.29 \%$ removal rate in $30 \mathrm{~min}$, respectively. The adsorptions for all of the four ions reach equilibrium within $\sim 1$ min (Fig. 2a), which is more faster than that of the previously reported indole-based aerogel. ${ }^{34}$ The PTIA shows faster heavy metal ions adsorption due to the conjugation of coplanar three indole would form a relatively large binding area to capture heavy metal ions. 

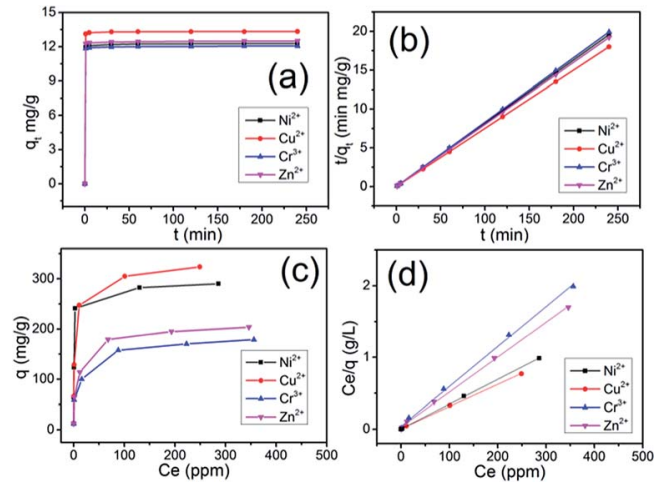

Fig. 2 Adsorption kinetics curves and sorption isotherms for $\mathrm{M}^{n+}\left(\mathrm{M}^{n+}\right.$ $=\mathrm{Ni}^{2+}, \mathrm{Cu}^{2+}, \mathrm{Cr}^{3+}, \mathrm{Zn}^{2+}$ ) by PTIA: (a) sorption capacity $\left(q_{t}\right)$ with time, (b) pseudo-second-order kinetic plots for sorption, Langmuir equilibrium isotherms were derived from equilibrium concentration $\left(C_{\mathrm{e}}, \mathrm{ppm}\right)$, plotted against the adsorption capacity (c) $q\left(\mathrm{mg} \mathrm{g}^{-1}\right)$ and (d) $C_{\mathrm{e}} / q_{\mathrm{e}}(\mathrm{g}$ $\left.L^{-1}\right)$.

The removal rate can be determined in two different ways: pseudo-first-order and pseudo-second-order mechanisms, which were defined as follows: ${ }^{38}$

Pseudo-first-order:

$$
\ln \left(q_{\mathrm{e}}-q_{t}\right)=\ln q_{\mathrm{e}}-k_{1} t
$$

Pseudo-second-order:

$$
\frac{t}{q_{t}}=\frac{1}{k_{2} q_{\mathrm{e}}^{2}}+\frac{t}{q_{\mathrm{e}}}
$$

where $q_{\mathrm{e}}\left(\mathrm{mg} \mathrm{g}^{-1}\right)$ is the adsorbed amount per unit mass of adsorbent at equilibrium and $q_{t}\left(\mathrm{mg} \mathrm{g}^{-1}\right)$ is the adsorbed mass at time $t$, while $k_{1}\left(\mathrm{~min}^{-1}\right)$ and $k_{2}\left(\mathrm{~g} \mathrm{mg}^{-1} \mathrm{~min}^{-1}\right)$ are corresponding equilibrium rate constants. The $k_{1}$ value was obtained by plotting $\ln \left(q_{\mathrm{e}}-q_{t}\right)$ against $t$ and the $k_{2}$ by plotting $t / q_{t}$ against $t$. The linear relationship of $t / q_{t}$ versus $t$ was presented in Fig. $2 \mathrm{~b}$. From the kinetic parameters of $\mathrm{Ni}^{2+}, \mathrm{Cu}^{2+}, \mathrm{Cr}^{3+}$ and $\mathrm{Zn}^{2+}$ (Table $\mathrm{S} 5 \dagger)$, the calculated sorption capacities $\left(q_{\mathrm{e}, \mathrm{cal}}\right)$ derived from the pseudo-second-order model are quite close to corresponding experimental values $\left(q_{\mathrm{e}, \exp }\right)$. The fit coefficient $\left(R_{2}\right)$ of 1 indicates the adsorption is well fitted with the pseudo-second-order kinetic model, suggesting a chemisorption process. ${ }^{39}$

Uptake capacity toward $\mathrm{Ni}^{2+}, \mathrm{Cu}^{2+}, \mathrm{Cr}^{3+}$ and $\mathrm{Zn}^{2+}$ by PTIA from aqueous solutions was studied with the batch method at room temperature. The maximum adsorption capacity of the material was determined from an adsorption equilibrium study. The $\mathrm{Ni}^{2+}$ capture by PTIA was found to increase successively with increasing concentration (10-500 ppm, Table S6 $\dagger$ ). Over a wide range of the initial concentration (10$100 \mathrm{ppm}$ ), the $\mathrm{Ni}^{2+}$ removal rates reached values of $>99 \%$, with the $K_{\mathrm{d}}^{\mathrm{Ni}}$ values ranging from $2.2 \times 10^{5}$ to $1.4 \times 10^{7} \mathrm{~mL} \mathrm{~g}^{-1}$. The maximum removal capacity $\left(q_{\mathrm{m}}\right)$ for $\mathrm{Ni}^{2+}$ reached $\sim 290.0 \mathrm{mg}$ $\mathrm{g}^{-1}$. This is an exceptionally high capacity competing with those of the best absorbers such as PMCNa hybrid hydrogels (224 $\left.\mathrm{mg} \mathrm{g}^{-1}\right),{ }^{40}$ for which adsorption capacities of various adsorbents are shown in Table S11. $\dagger$ We also checked the adsorption of the PTIA material for $\mathrm{Cu}^{2+}$ in the range of concentrations $10 \mathrm{ppm}$ to $500 \mathrm{ppm}$ (Table S7 $\dagger$ ), and found that there are $>99 \%$ removal rates in the initial concentration (10$100 \mathrm{ppm}$ ), and $\sim 323 \mathrm{mg} \mathrm{g}^{-1}$ maximum adsorption capacity, this value is still very high compared to reported adsorbents (Table $\mathrm{S} 11 \dagger$ ). For $\mathrm{Cr}^{3+}$ and $\mathrm{Zn}^{2+}$, the maximum adsorption capacity is found to be relatively lower at $\sim 178.8 \mathrm{mg} \mathrm{g}^{-1}$ and $203.8 \mathrm{mg} \mathrm{g}^{-1}$ (Tables S8 and S9†), however those value is still very high compared to reported adsorbents (Table S11†), which is higher than that of the previously reported indolebased aerogel. ${ }^{34}$ The PTIA shows higher heavy metal ions adsorption due to the conjugation of coplanar three indole would form a highly electron-rich large $\pi$ plane which can simultaneously attract six heavy metal via the double cation $-\pi$ interactions.

A Langmuir isotherm is used to describe the experimental data of $\mathrm{Ni}^{2+}, \mathrm{Cu}^{2+}, \mathrm{Cr}^{3+}$ and $\mathrm{Zn}^{2+}$. In this model, the adsorbate moieties $\left(\mathrm{Ni}^{2+}, \mathrm{Cu}^{2+}, \mathrm{Cr}^{3+}, \mathrm{Zn}^{2+}\right)$ are assumed to undergo monolayer type coverage of the sorbent on an adsorbent surface. Once an adsorption site is occupied, no further adsorption can happen at the same site. The Langmuir isotherm model is listed as equation:

$$
q=q_{\mathrm{m}} \frac{b C_{\mathrm{e}}}{1+b C_{\mathrm{e}}}
$$

where $q\left(\mathrm{mg} \mathrm{g}^{-1}\right)$ is the equilibrium adsorption capacity of $\mathrm{Ni}^{2+}$, $\mathrm{Cu}^{2+}, \mathrm{Cr}^{3+}$ and $\mathrm{Zn}^{2+}$ adsorbed, $C_{\mathrm{e}}\left(\mathrm{mg} \mathrm{L}^{-1}\right)$ is the $\mathrm{Ni}^{2+}, \mathrm{Cu}^{2+}, \mathrm{Cr}^{3+}$ and $\mathrm{Zn}^{2+}$ concentration at equilibrium, $q_{\mathrm{m}}\left(\mathrm{mg} \mathrm{g}^{-1}\right)$ is the theoretical maximum sorption capacity. The equilibrium adsorption isotherms are shown in Fig. 2c, with the $\mathrm{Ni}^{2+}, \mathrm{Cu}^{2+}$, $\mathrm{Cr}^{3+}$ and $\mathrm{Zn}^{2+}$ equilibrium concentration ranging from 0.0005 to $356 \mathrm{ppm}$. The experimental data of uptake capacity for $\mathrm{Ni}^{2+}$, $\mathrm{Cu}^{2+}, \mathrm{Cr}^{3+}$ and $\mathrm{Zn}^{2+}$ are fitted well with the Langmuir isotherm model of eqn (3), see Fig. 2d. According to the Langmuir isotherm model, the expected capacity $q_{\mathrm{m}}$ of $289.9 .5 \mathrm{mg} \mathrm{g}^{-1}$ for $\mathrm{Ni}^{2+}$, of $323.6 \mathrm{mg} \mathrm{g}^{-1}$ for $\mathrm{Cu}^{2+}$, of $179.9 \mathrm{mg} \mathrm{g}^{-1}$ for $\mathrm{Cr}^{3+}$ and of $205.3 \mathrm{mg} \mathrm{g}^{-1}$ for $\mathrm{Zn}^{2+}$, which are consistent with the experimental value of $290.0 \mathrm{mg} \mathrm{g}^{-1}$ for $\mathrm{Ni}^{2+}$, of $323.8 \mathrm{mg} \mathrm{g}^{-1}$ for $\mathrm{Cu}^{2+}$, of $178.8 \mathrm{mg} \mathrm{g}^{-1}$ for $\mathrm{Cr}^{3+}$ and of $203.8 \mathrm{mg} \mathrm{g}^{-1}$ for $\mathrm{Zn}^{2+}$. The large correlation coefficient $\left(R^{2}>0.99\right)$ shows a good fit with the Langmuir isotherm, suggesting a monolayer adsorption ${ }^{\mathbf{4 1}}$ on the PTIA (Table S10†).

Fig. S9† shows $\mathrm{Ni}^{2+}, \mathrm{Cu}^{2+}, \mathrm{Cr}^{3+}$ and $\mathrm{Zn}^{2+}$ adsorption recycled for 4 times, after 1 cycles reused, metal ions adsorption decreased most, which may due to that part metal ions, that not be desorbed by $\mathrm{HCl}$, occupied part of the adsorption sites. The metal ions adsorption for regeneration 2, 3 and 4 times were relatively close to each other. After 4 cycles reused, the amount of metal ions adsorption for $\mathrm{Ni}^{2+}, \mathrm{Cu}^{2+}, \mathrm{Cr}^{3+}$ and $\mathrm{Zn}^{2+}$ ions was $90,103,75$ and $92 \mathrm{mg} \mathrm{g}^{-1}$, which was $74.6 \%, 80.2 \%, 75.0 \%$ and $81.4 \%$ of adsorption for the fresh sample, respectively. The excellent recyclability of the metal ions on PTIA is very helpful for practical applications, suggesting the long-term use in water purification.

To identify the interaction between PTIA samples and heavy metal ions during the adsorption process, UV absorption was performed. Fig. 3a shows the absorption spectra of 10,15-dihydro-5H-diindolo[3,2- $\left.a: 3^{\prime}, 2^{\prime}-c\right]$ carbazole (TAT) in the 


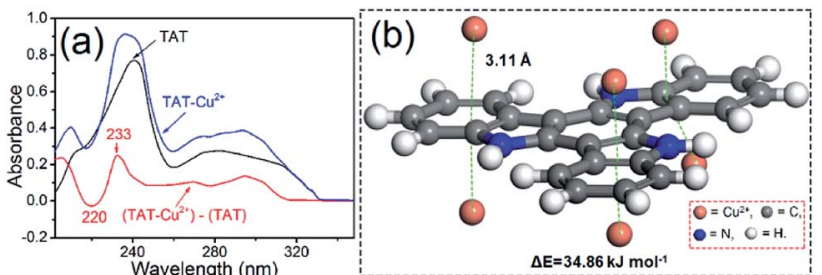

Fig. 3 (a) UV absorption spectra of TAT $(100 \mu \mathrm{M})$ and its $1: 1$ complex with $\mathrm{Cu}^{2+}$ at $\mathrm{pH} 7$ (1 mM HEPES buffer), (b) fully optimized geometries of model interactions calculated using DFT method: the double cation $-\pi$ conformation of PTIA with $\mathrm{Cu}^{2+}$.

absence and presence of equimolar $\mathrm{Cu}^{2+}$, together with the difference spectrum TAT- $\mathrm{Cu}^{2+}$ minus TAT. The difference spectrum TAT- $\mathrm{Cu}^{2+}$ (red line) reveals a negative band at $220 \mathrm{~nm}$ and a positive band at $233 \mathrm{~nm}$ attributable to $\mathrm{a} \mathrm{Cu}^{2+}$ TAT interaction. An analogous UV difference spectrum with a negative/positive band pair around $220 / 230 \mathrm{~nm}$ has been observed for an indolyl model compound of the cation- $\pi$ interaction, ${ }^{42}$ a cation- $\pi$ interaction between a positively charged His imidazole ring and a nearby Trp indole ring has also been reported to produce an analogous band pair. ${ }^{43}$ The similarity of the UV difference spectrum of TAT- $\mathrm{Cu}^{2+}$ with those reported previously for other types of cation- $\pi$ interactions indicates that the TAT interaction in TAT $-\mathrm{Cu}^{2+}$ is also categorized as a cation $-\pi$ interaction. To elucidate the adsorption mechanism, the Density Functional Density (DFT) calculations were performed to investigate the interactions between PTIA and $\mathrm{Cu}^{2+},{ }^{44-46}$ the calculations were detailed in ESI. $\uparrow$ The snapshot of $\mathrm{Cu}^{2+}$ adsorption are shown in Fig. 3b. The figure shows a minimized geometry of the model compound. The equilibrium conformation of $\mathrm{Cu}^{2+}$ TAT is six electron-deficient $\mathrm{Cu}^{2+}$ and the coplanar three indole ring forming sandwichy cation $-\pi$ configuration with the distance of $3.11 \AA$, and the computational binding energy is $34.86 \mathrm{~kJ} \mathrm{~mol}^{-1}$ (Fig. $3 \mathrm{~b}$ ). $\mathrm{Cu}^{2+}$ can be easily and rapidly adsorbed on the coplanar three indole ring due to its relatively large binding area through double cation- $\pi$ interactions.

\section{Conclusions}

In summary, we have rationally designed a new type of indolebased conjugated microporous polymer (PTIA) that is easily prepared in the presence of the $\mathrm{FeCl}_{3}$ catalyst by a facile direct oxidative coupling reaction. We have demonstrated that the conjugated microporous polymer could be used as a high effective and extraction material for heavy metals from aqueous solution through the conjugation of coplanar three indole would form a highly electron-rich large $\pi$ plane which can simultaneously attract six heavy metal via the double cation- $\pi$ interactions.

\section{Conflicts of interest}

There are no conflicts to declare.

\section{Notes and references}

1 J. O. Nriagu and J. M. Pacyna, Nature, 1988, 333, 134.

2 R. P. Schwarzenbach, B. I. Escher, K. Fenner, T. B. Hofstetter, C. A. Johnson, U. V. Gunten and B. Wehrli, Science, 2006, 313, 1072 .

3 L. Yang, C. Wang, G. Chang and X. Ren, Sens. Actuators, B, 2017, 240, 212.

4 S. Basak, N. Nandi, S. Paul, I. W. Hamley and A. Banerjee, Chem. Commun., 2017, 53, 5910.

5 L. Wang, D. Hu, X. Kong, J. Liu, X. Li, K. Zhou, H. Zhao and C. Zhou, Chem. Eng. J., 2018, 346, 38.

6 Q. Feng, D. Wu, Y. Zhao, A. Wei, Q. Wei and H. Fong, J. Hazard. Mater., 2018, 344, 819.

7 Y. Shi, T. Zhang, H. Ren, A. Kruse and R. Cui, Bioresour. Technol., 2018, 247, 370.

8 L. Brinza, K. Geraki, I. G. Breaban and M. Neamtu, J. Hazard. Mater., 2019, 365, 252-260.

9 P. Fang, Z. Tang, X. Chen, J. Huang, Z. Tang and C. Cen, J. Chem., 2018, 2018, 1-9.

10 T. Saito, S. Brown, S. Chatterjee, J. Kim, C. Tsouris, R. T. Mayes, L. J. Kuo, G. Gill, Y. Oyola and C. J. Janke, J. Mater. Chem. A, 2014, 2, 14674.

11 Y. Shimazaki, T. Yajima, M. Takani and O. Yamauchi, Coord. Chem. Rev., 2009, 253, 479.

12 C. Fischer, M. Oschatz, W. Nickel, D. Leistenschneider, S. Kaskel and E. Brunner, Chem. Commun., 2017, 53, 4845.

13 L. Dong, L. a. Hou, Z. Wang, P. Gu, G. Chen and R. Jiang, J. Hazard. Mater., 2018, 359, 76.

14 A. Ma, A. Abushaikha, S. J. Allen and G. McKay, Chem. Eng. J., 2019, 358, 1.

15 I. K. Moideen, A. M. Isloor, A. A. Qaiser, A. F. Ismail and M. S. Abdullah, Korean J. Chem. Eng., 2018, 35, 1281.

16 G. Zhao, X. Huang, Z. Tang, Q. Huang, F. Niu and X. Wang, Polym. Chem., 2018, 9, 3562.

17 H. Chen, J. Lin, N. Zhang, L. Chen, S. Zhong, Y. Wang, W. Zhang and Q. Ling, J. Hazard. Mater., 2018, 345, 1.

18 B. Aguila, Q. Sun, J. A. Perman, L. D. Earl, C. W. Abney, R. Elzein, R. Schlaf and S. Ma, Adv. Mater., 2017, 29, 1700665.

19 B. Hayati, A. Maleki, F. Najafi, H. Daraei, F. Gharibi and G. McKay, J. Hazard. Mater., 2017, 336, 146.

20 S. Zhang, J. Wen, Y. Hu, Y. Fang, H. Zhang, L. Xing, Y. Wang and G. Zeng, J. Hazard. Mater., 2019, 366, 210.

21 F. P. Silvas, M. M. J. Correa, M. P. Caldas, V. T. de Moraes, D. C. Espinosa and J. A. Tenório, Waste Manag., 2015, 46, 503.

22 X. Liu, Q. Tan, Y. Li, Z. Xu and M. Chen, Front. Environ. Sci. Eng., 2017, 11, 10.

23 G. Arrabito, V. Errico, Z. Zhang, W. Han and C. Falconi, Nano Energy, 2018, 46, 54-62.

24 M. Liu, C. Yao, C. Liu and Y. Xu, Sci. Rep., 2018, 8, 14072.

25 Y. Fu, W. Yu, W. Zhang, Q. Huang, J. Yan, C. Pan and G. Yu, Polym. Chem., 2018, 9, 4125.

26 M. Xu, T. Wang, P. Gao, L. Zhao, L. Zhou and D. Hua, J. Mater. Chem. A, 2019, 7, 11214.

27 M. Xu, X. Han, T. Wang, S. Li and D. Hua, J. Mater. Chem. A, 2018, 6, 13894. 
28 D. Dai, Z. Li, J. Yang, C. Wang, J.-R. Wu, Y. Wang, D. Zhang and Y. W. Yang, J. Am. Chem. Soc., 2019, 141, 4756.

29 G. Chang, Y. Wang, C. Wang, Y. Li, Y. Xu and L. Yang, Chem. Commun., 2018, 54, 9785.

30 G. Chang, Z. Shang, T. Yu and L. Yang, J. Mater. Chem. A, 2016, 4, 2517.

31 W. Wei, G. Chang, Y. Xu and L. Yang, J. Mater. Chem. A, 2018, 6, 18794.

32 G. Chang, L. Yang, J. Yang, M. P. Stoykovich, X. Deng, J. Cui and D. Wang, Adv. Mater., 2018, 30, 1704234.

33 K. Wang, L. Yang, W. Wei, L. Zhang and G. Chang, J. Membr. Sci., 2018, 549, 23.

34 P. Yang, L. Yang, Y. Wang, L. Song, J. Yang and G. Chang, J. Mater. Chem. A, 2019, 7, 531.

35 G. Leofanti, M. Padovan, G. Tozzola and B. Venturelli, Catal. Today, 1998, 90, 207.

36 X. Zhu, S. M. Mahurin, S. H. An, C. L. Dothanh, C. Tian, Y. Li, L. W. Gill, E. W. Hagaman, Z. Bian and J. H. Zhou, Chem. Commun., 2014, 50, 7933.

37 A. Vishnyakov, P. I. Ravikovitch and A. V. Neimark, Langmuir, 1999, 15, 8736.
38 S. Azizian, J. Colloid Interface Sci., 2004, 276, 47.

39 T. Liu, M. Yang, T. Wang and Q. Yuan, Ind. Eng. Chem. Res., 2012, 51, 454.

40 P. M. Spasojevic, V. V. Panic, M. D. Jovic, J. Markovic, C. V. Roost, I. G. Popovic and S. J. Velickovic, J. Mater. Chem. A, 2016, 4, 1680.

41 A. Farrukh, A. Akram, A. Ghaffar, S. Hanif, A. Hamid, H. Duran and B. Yameen, ACS Appl. Mater. Interfaces, 2013, 5, 3784 .

42 A. Okada, T. Miura and H. Takeuchi, Biochemistry, 2001, 40, 6053.

43 S. L. De Wall, E. S. Meadows, L. J. Barbour and G. W. Gokel, J. Am. Chem. Soc., 1999, 121, 5613.

44 W. Wang, C. Zhu and Y. Cao, Int. J. Hydrogen Energy, 2010, 35, 1951.

45 S. Qu, X. Chen, X. Shao, F. Li, H. Zhang, H. Wang, P. Zhang, Z. Yu, K. Wu, Y. Wang and M. Li, J. Mater. Chem., 2008, 18, 3854.

46 R. Lü, J. Lin and Z. Qu, Comput. Theor. Chem., 2012, 1002, 49. 